\title{
Integrated Braking Force Distribution for Electric Vehicle Regenerative Braking System
}

\author{
Anith Khairunnisa Ghazali ${ }^{1}$, Mohd Khair Hassan ${ }^{1 *}$, Mohd Amran Mohd Radzi ${ }^{1}$ \\ and Azizan As'arry ${ }^{2}$ \\ ${ }^{1}$ Department of Electrical and Electronic, Faculty of Engineering, Universiti Putra Malaysia, \\ 43400 Serdang, Selangor, Malaysia \\ ${ }^{2}$ Department of Mechanical and Manufacturing, Faculty of Engineering, Universiti Putra Malaysia, \\ 43400 Serdang, Selangor, Malaysia
}

\begin{abstract}
The automotive industry has made a significant contribution to everyday life by fulfilling society's mobility needs. Traditionally, electric vehicles (EV) were introduced as an alternative to the traditional internal combustion engine (ICE) to reduce the emission, which improves air quality. The regenerative braking system (RBS) technology is increasing rapidly as an alternative energy-saving solution instead of using the conventional fossil fuel process. In addition, conventional braking creates energy loss because it produces unnecessary heat during braking. Therefore, (RBS) was deliberately designed to solve these drawbacks. Several researchers have found an efficient way to recover regenerative energy, but do not pay enough attention to state-of-the-art (SOC), motor performance and overall performance. This paper designs a new braking force distribution that introduces integrated braking by combining the default ADVISOR and the new parallel braking distribution to improve the SOC battery for three driving cycles. The design of the braking part was based on the braking force distribution of vehicle speed, consisting mainly of friction and regenerative braking ratio allocation in parallel form. The suggested delivery method is evaluated by simulation and shows that

ARTICLE INFO

Article history:

Received: 10 February 2020

Accepted: 13 November 2020

Published: 31 December 2020

DOI: https://doi.org/10.47836/pjst.28.S2.14 the overall performance and battery life are increased. The proposed method was experimentally evaluated using ADVISOR Matlab for the efficiency and final state of the battery.
\end{abstract}

E-mail addresses:

akg_anith@yahoo.com (Anith Khairunnisa Ghazali)

khair@upm.edu.my (Mohd Khair Hassan)

amranmr@upm.edu.my (Mohd Amran Mohd Radzi)

zizan@upm.edu.my (Azizan As'arry)

* Corresponding author

Keywords: Braking force distribution, electric vehicles, regenerative braking 


\section{INTRODUCTION}

One of the most vital features of electricity based vehicle is their ability to recuperate the braking energy. Recovering and reusing the process of braking energy able to improve the fuel economy which is focused on frequent braking events such as urban driving. Due to the shortage of fossil fuel sources and environmental pollution issues, alternative fuels and hybrid technology has received vast attention (Zhang et al., 2013). Nowadays, many automotive industries produce electric vehicles as a solution. However, limited driving mileage becomes a critical issue. During the charging process, the time taken for the battery to reach full charge is high. Due to this factor, electric vehicle technology are still not at the satisfied level (Kiyakli \& Solmaz, 2019). The main consideration during braking system design must be the braking performance that braking system design should be able to stop or slow down the vehicle as fast as possible and keep the vehicle in stable condition as well. (Goodarzi et al., 2008). In order to produce better braking performance and improve regenerative braking efficiency, an integrated braking strategy has been proposed in this research. The performance of the battery state of charge is analyzed and verified through simulation results.

One of the most vital features of electricity based vehicle is their capability to recuperate the braking energy. The recovering process of braking energy able to improve the fuel economy which is focused on frequent braking events such as urban driving. Consequently, cooperation between regenerative and frictional braking systems of electrified vehicles is important for vehicle control in safety driving manoeuvres (Lv et al., 2015).

In general, the electric motor in electric vehicle (EV) works as an alternator to transform mechanical energy into electrical energy. The captured energy will store in energy storage for future usage ( $\mathrm{Lv}$ et al., 2015). To slow down the vehicle, the braking torque required must be larger than torque produced by the electric motor. To improve regenerative efficiency, braking torque has to be designed. The vehicle speed based of braking distribution is considered in this research. Most of EV used a combination of frictional braking and regenerative braking. Therefore, the appropriate design of good braking distribution is a major attention. The main issue designing the braking distribution is to consider the safety and ensure the battery condition without overcharging. The crucial topic in constructing the regenerative braking system is the method to allocate the overall braking forces required between the regenerative and frictional brake in order to capture and convert optimum kinetic energy into electrical energy. During deceleration, the braking force should distribute the highest ratio to the front axle to improve braking energy recovery. At lower speed, the energy recovered is minimal and it is difficult to reach the demands of the pedal drivers (Yeo \& Kim, 2002). In general, the proposed method of regulating energy savings and its impact is clear and apparent. 


\section{METHODS}

Figure 1 below illustrates the electric vehicle driving process model. This model is used to evaluate the state of charge battery and braking performance in this research. The major component consists of driver block, brake strategy, battery, motor and vehicle model.

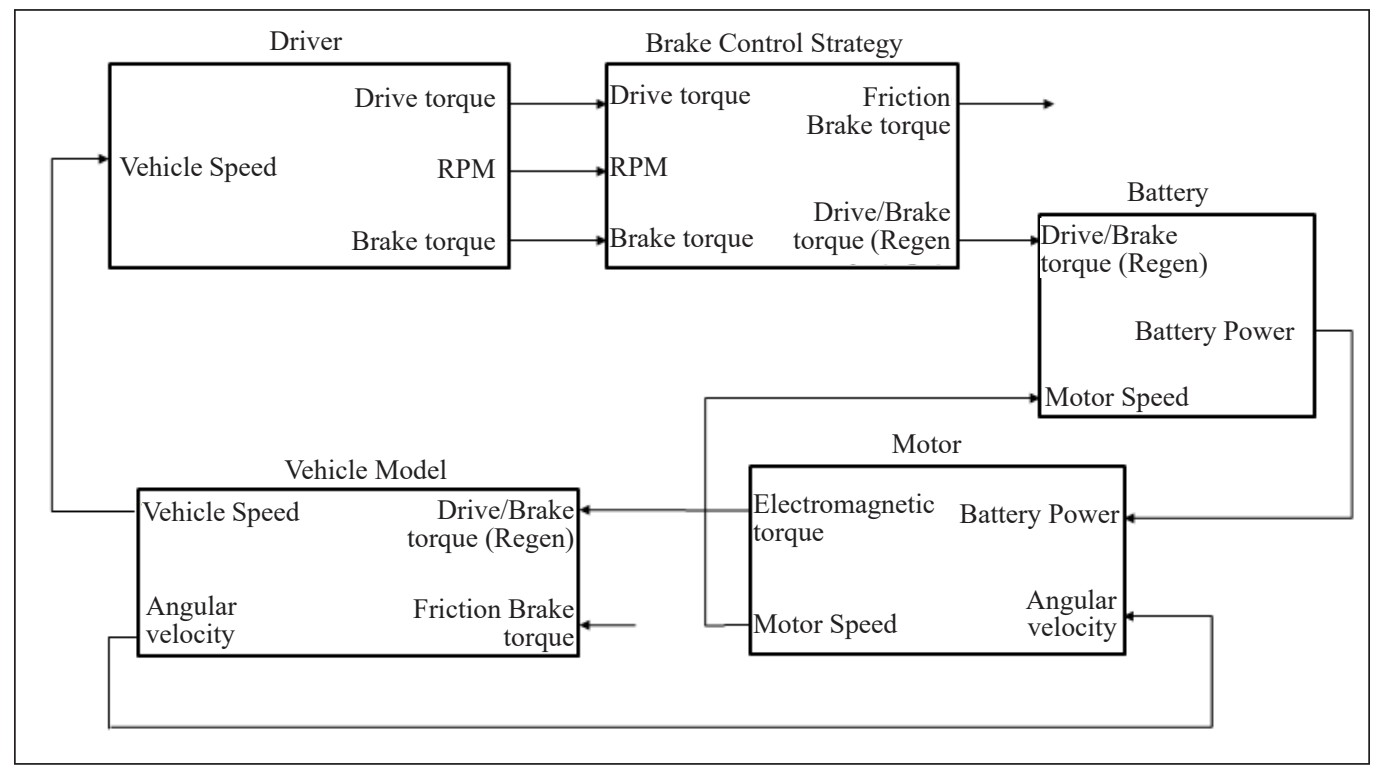

Figure 1. Electric vehicle block diagram

\section{Vehicle Dynamics}

The longitudinal dynamics of the vehicle during the deceleration process can be modeled by considering aerodynamic resistance, rolling resistance, and gradient resistance (Mehrdad et al., 2005).

Aerodynamic resistance is a force which the oncoming air applies on a moving body. The equation expresses as:

$$
F_{a}=0.5 \rho C_{d} A_{f}(\Delta V)^{2}
$$

Where, $\mathrm{C}_{\mathrm{d}}$ is the coefficient of air resistance, $\mathrm{A}_{\mathrm{f}}$ is windward are, $\rho$ is the air density and $\Delta V$ is the differential speed between vehicle and air. The rolling resistance is the energy that vehicles pass through tires to maintain movement at a regular speed over a surface. The tire rolling resistance is calculated with this equality:

$$
F_{r}=m g C_{r} \cos \alpha
$$

Where $C_{r}$ is the coefficient of rolling resistance, $m$ is the total weight and $\alpha$ is the angle. Next, the gradient resistance appears due to the component of gravity. When a vehicle 
goes up or down a slope, the weight component always directed a downward direction. The equation for gradient resistance formulated as:

$$
F_{g}=m g \sin \alpha
$$

\section{Braking Distribution Strategy}

The parallel strategy distributes the regenerative and friction based on vehicle speed. Furthermore, vehicle speed high influence in ensuring the braking safety. Therefore during the design process of regenerative braking distribution, considering the vehicle speed is vital. Figure 2 describes the motor efficiency map during operation. At low speed of the vehicle the regenerative should be minimal due to the smallest kinetic energy. Next, when the speed is increasing at the middle range, the regenerative braking should increase to a certain range. During accelerating at high speed, the regenerative braking should be high due to great kinetic energy of motor (Gang \& Zhi, 2018).

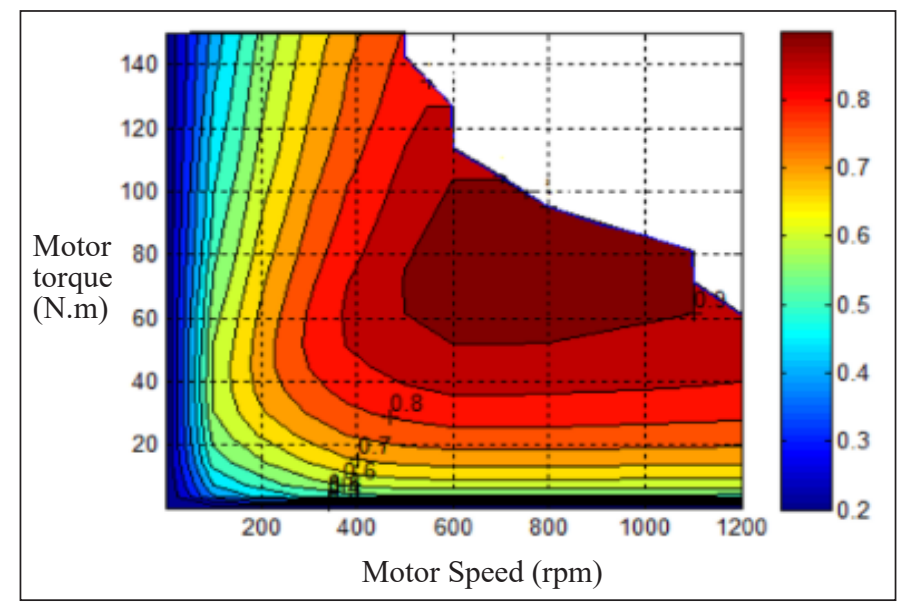

Figure 2. Motor map efficiency

Figure 3 shows the new parallel braking control strategy based on vehicle speed. This technique operates regenerative and friction at the same time during the braking process. A standard look-up table for the distribution of the brake forces provided by the regenerative and frictional brakes is shown in Figure 3. The rationale behind this approach is that the recovery energy decrease at lower speed and increase at higher speed (Zhou et al., 2011). The regenerative braking coefficient is the ratio of regenerative braking torque and total braking torque in between the range 0 to 1 . The balance of braking is carried out by certain vehicle resistances such as aerodynamic resistance, initial losses, rolling resistance, etc. (Panagiotidis et al., 2018). The regenerative ratio is higher during high acceleration and during the lower speed of vehicle, regenerative does not work and friction brake takes place (Zhang et al., 2019). 


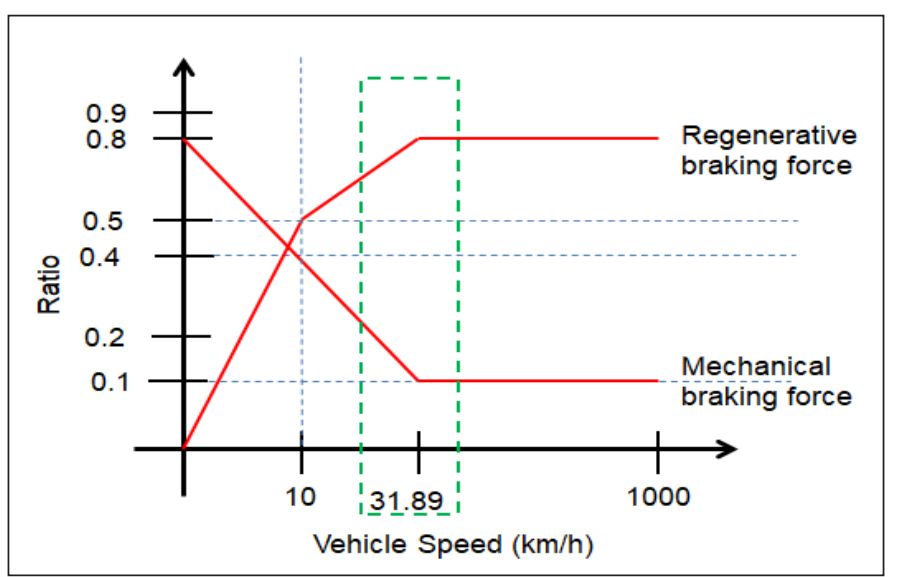

Figure 3. New parallel braking force distribution

In this research, the new proposed braking strategy introduces average speed due to the most frequent speed implement during urban driving as the highest ratio of regenerative braking instead of using the ADVISOR default technique design that introduces the highest ratio of regenerative braking at standard speed which is $60 \mathrm{~km} / \mathrm{h}$. According to Mahayadin et al.'s (2018) findings, urban driving Malaysia's average speed is $31.89 \mathrm{~km} / \mathrm{h}$.

Figure 4 shows the integrated braking strategy proposed in this paper. The integrated braking is a combination of default braking system and parallel braking that uses Malaysia's average speed for high regenerative braking ratio. The merits of applying such strategy are to improve as well as to enhance the performance of regenerative braking by determining appropriate braking ratio coefficient that should be implemented during deceleration. The new parallel braking force distribution will act as tuning component in order to optimize recovered energy to optimum output.

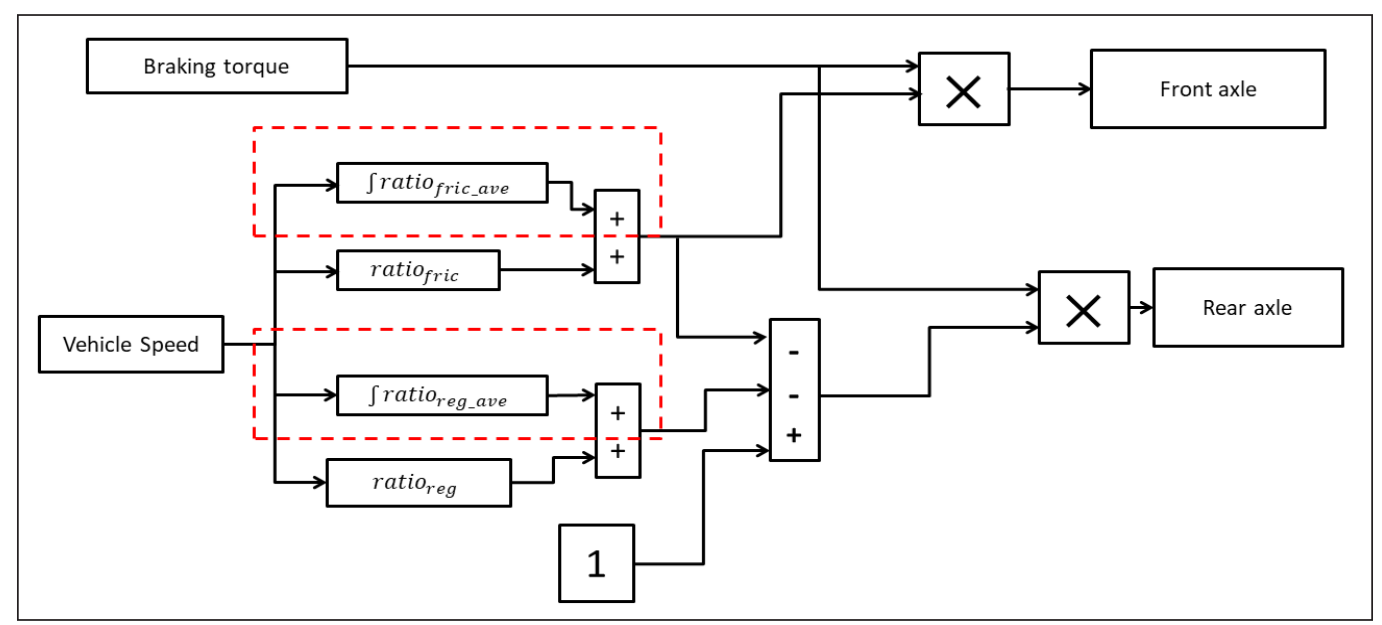

Figure 4. Integrated braking strategy 


$$
T_{\text {tot }}=T_{\text {fric }}+T_{\text {reg }}
$$

$\mathrm{T}_{\text {tot }}=$ Total braking torque request

$\mathrm{T}_{\text {fric }}$ is the friction braking of front and rear axle, $\mathrm{T}_{\mathrm{reg}}$ is the regenerative braking of rear axle.

The distribution for friction and regenerative distribution at rear axle express as:

$$
\begin{aligned}
& T_{r}=T_{r_{-} \text {fric }}+T_{r_{-} r e g} \\
& T_{r_{-} \text {gen }}=T_{r} \cdot\left(\text { ratio }_{\text {reg }}+\text { ratio }_{\text {reg }_{-} a v e}\right) \\
& T_{r_{-} \text {fric }}=T_{r} \cdot\left(1-\left(\text { ratio }_{\text {fric }}+\text { ratio }_{\text {fric_ave }}\right)-\left(\text { ratio }_{\text {reg }}+\text { ratio }_{\text {reg_ave }}\right)\right)
\end{aligned}
$$

$\mathrm{T}_{\mathrm{r}_{-} \text {fric }}$ and $\mathrm{T}_{\mathrm{r}_{-} \text {reg }}$ represent the friction braking torque request for friction and regenerative of rear axle. The ratio fric $_{\text {fric }}$, ratio fric _ave, $_{\text {ratio }}$ reg and ratio ${ }_{\text {reg_ave }}$ denotes as brake distribution coefficient for friction and regenerative braking.

\section{RESULTS}

\section{Simulation Result}

To determine the performance of the proposed braking strategy, vehicle driving simulation had been completed using NEDC and US06 drive cycle. Drive cycle is driving pattern that represents actual driving behavior for experimental purpose. The aim of a drive cycle is to decrease the time and cost of an expensive on-road test. This research used NEDC for urban driving and US06 for high acceleration driving behavior (Mcdonald et al., 2012). The driving behavior of NEDC and US06 are shown in Figures 5 and 6.

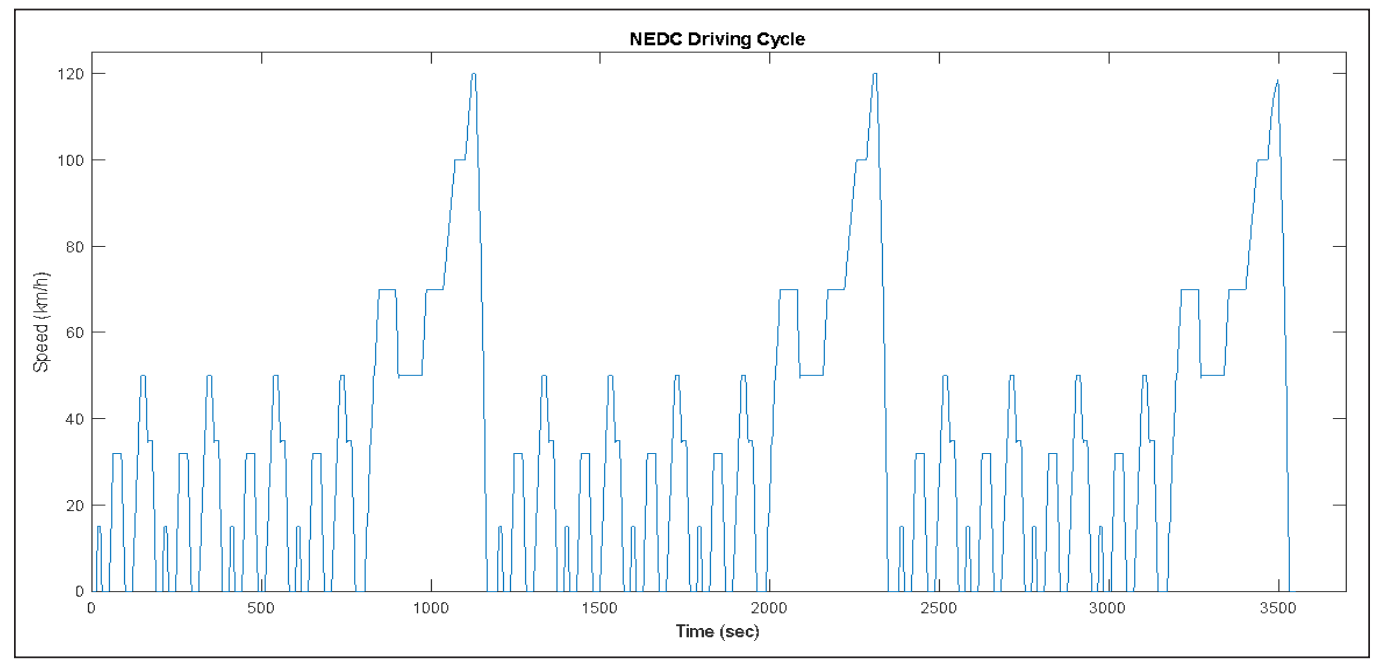

Figure 5. NEDC driving cycle 


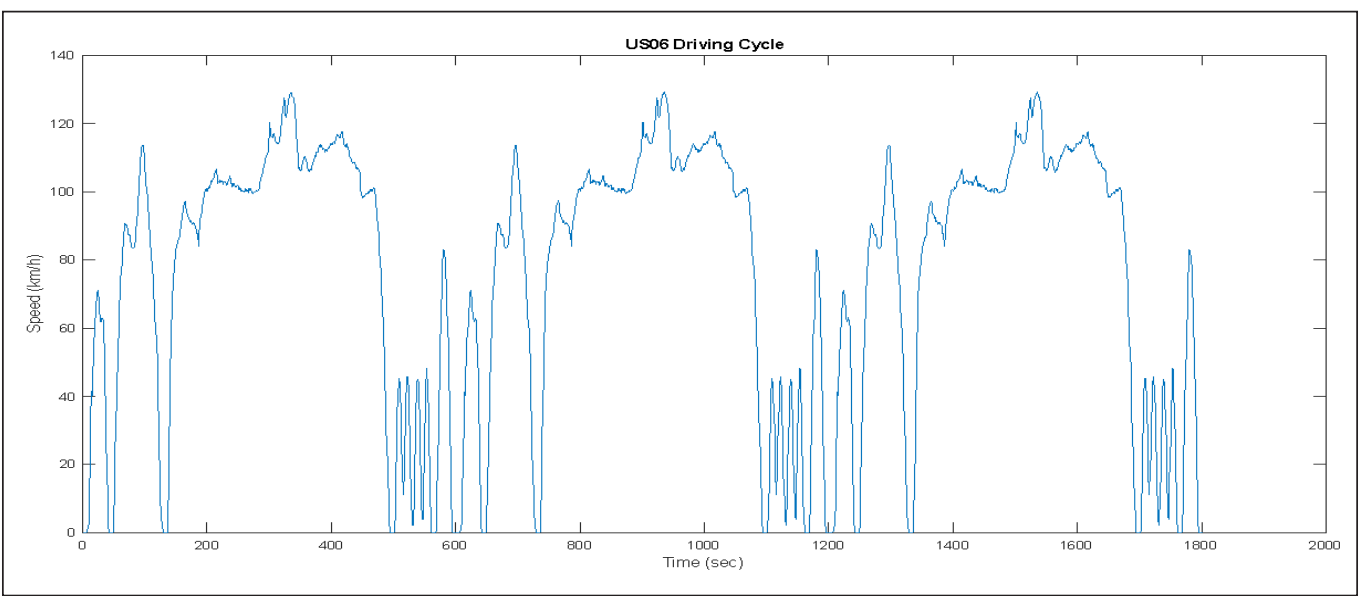

Figure 6. US06 driving cycle

Simulation results of NEDC state of charge is presented in Figure 7. Based on this, the output, the first cycle of NEDC for integrated strategy did not recover much energy to avoid overcharging at $90 \%$ of the battery level. The consequences of integrated braking could be seen from the second cycle where the ratio SOC dropped about 0.98 and at the third cycle, the SOC increased to about 0.023 . This is due to the tuning components that purposely optimize the SOC to the optimum value. The final value of SOC for the default strategy was 0.3375 , while the SOC value for the integrated strategy was 0.7329 higher than default. Table 1 summarizes the brake loss, energy transmitted, motor efficiency and overall efficiency. Comparing to the default strategy, the brake loss for integrated strategy was 43485 higher than the default strategy. However, the energy transmitted regenerative purpose improved to 3031 , motor efficiency improved to 0.85 and overall efficiency was 0.601 .

The driving performance of US06 obtained is recorded in Table 2. It is clearly visible that the brake loss using integrated braking strategy was reduced to $30 \mathrm{~kJ}$, while the energy transmitted improved to $231530 \mathrm{~kJ}$. Next, the motor efficiency was reduced to 0.76 but still was in high motor efficiency range and the overall efficiency increased to 0.952 . The state of charge for US06 improved from 0.024 to 0.3657 as illustrated in Figure 8.

Table 1

NEDC driving performance

\begin{tabular}{lccc}
\hline & Default & Integrated & Improvement \\
\hline Brake loss $(\mathrm{kJ})$ & 2555 & 45775 & 43485 \\
Energy transmitted $(\mathrm{kJ})$ & 4599 & 88734 & 3031 \\
Motor efficiency & 0.67 & 0.85 & 0.18 \\
Overall efficiency & 0.434 & 1.758 & 0.601 \\
\hline
\end{tabular}


Table 2

US06 driving performance

\begin{tabular}{lccc}
\hline & Default & Integrated & Improvement \\
\hline Brake loss $(\mathrm{kJ})$ & 3500 & 162680 & -30 \\
Energy transmitted $(\mathrm{kJ})$ & 6299 & 231530 & 206440 \\
Motor efficiency & 0.81 & 0.76 & 0.02 \\
Overall efficiency & 0.529 & 0.952 & 0.21 \\
\hline
\end{tabular}

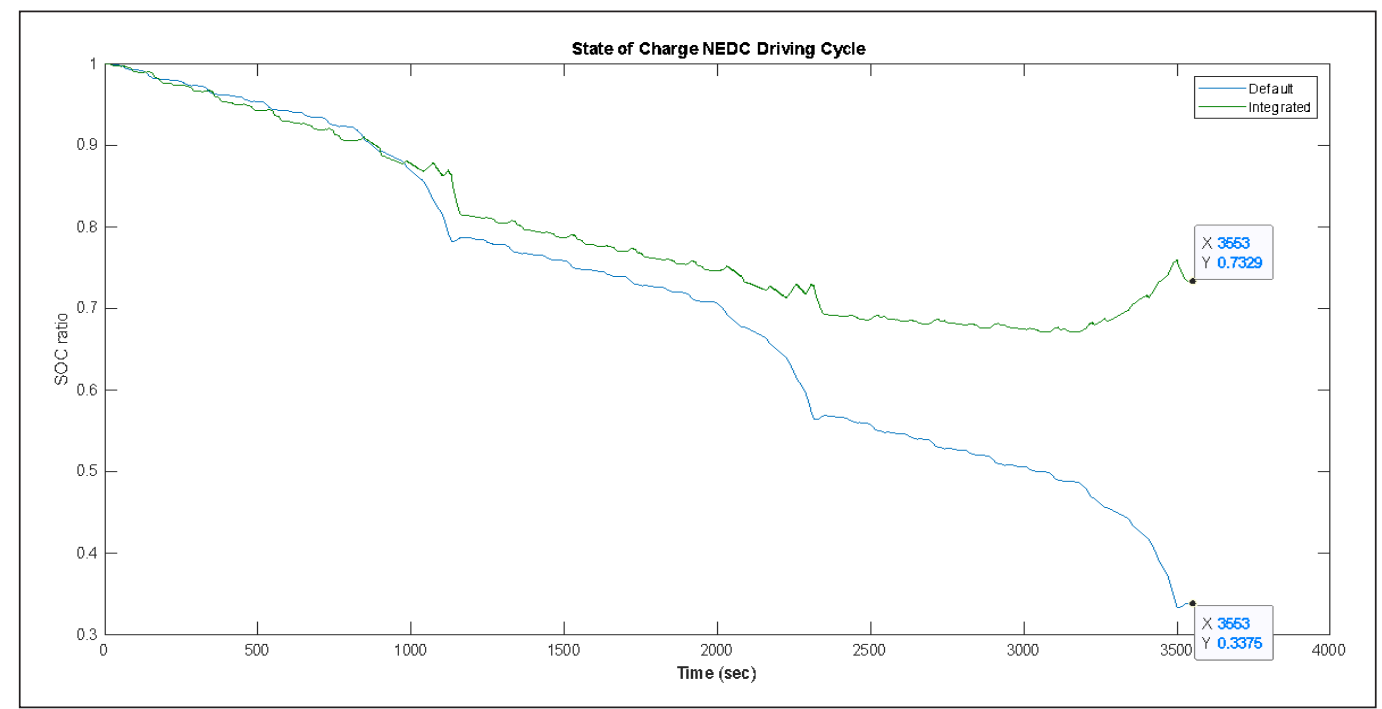

Figure 7. NEDC state of charge

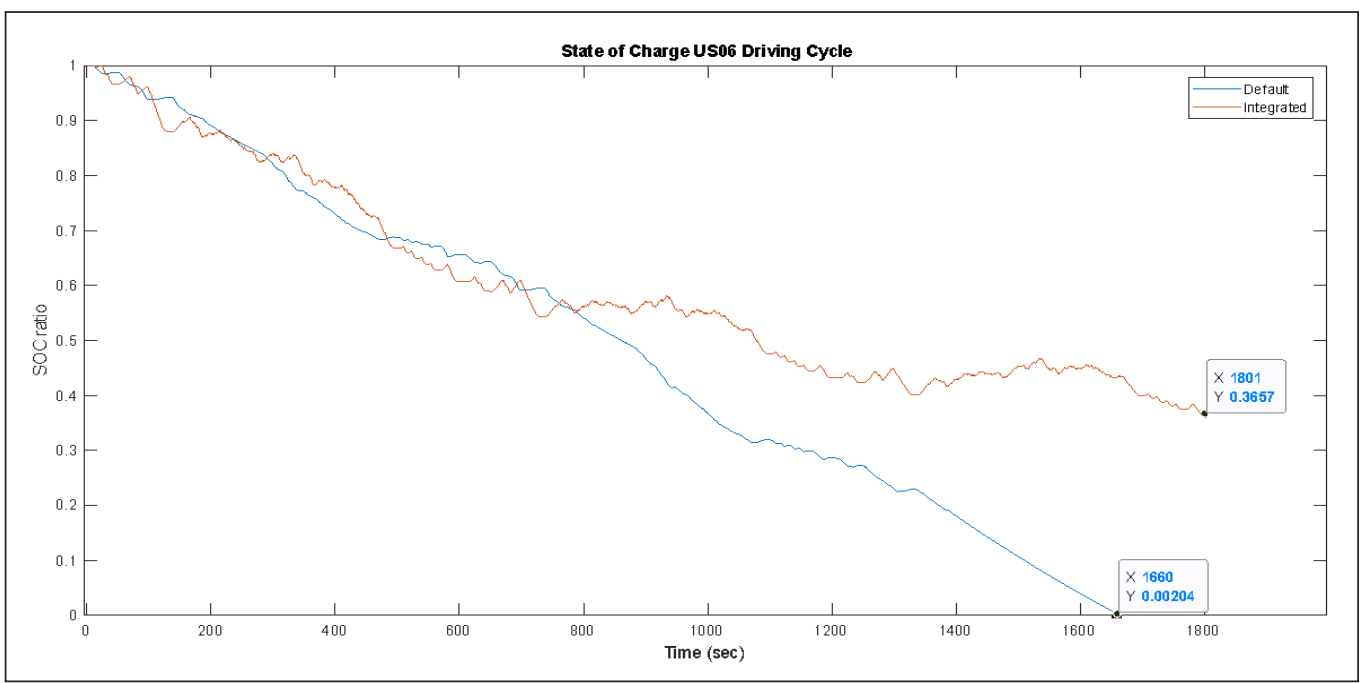

Figure 8. US06 state of charge 


\section{CONCLUSION}

This research proposed the regenerative braking system using integrated braking force distribution. In order to improve the energy efficiency of the electric vehicle, several parameters such as overall efficiency, energy transmitted, energy loss during driving and SOC battery had been taken in consideration. The simulation results show that the proposed braking strategy was able to improve the energy efficiency of the electric vehicle.

\section{ACKNOWLEDGEMENT}

The authors would like to thank Universiti Putra Malaysia for funding this project under Putra Grant with grant number GP/2018/9591900.

\section{REFERENCES}

Gang, L., \& Zhi, Y. (2018). Energy saving control based on motor efficiency map for electric vehicles with four-wheel independently driven in-wheel motors. Advances in Mechanical Engineering, 10(8), 1-18. doi:10.1177/1687814018793064

Goodarzi, A., Behmadi, M., \& Esmailzadeh, E. (2008). An optimised braking force distribution strategy for articulated vehicles. International Journal of Vehicle Mechanics and Mobility, 46(1), 849-856. doi:10.1080/00423110802037107

Kiyakli, A. O., \& Solmaz, H. (2019). Modeling of an electric vehicle with MATLAB/simulink. International Journal of Automotive Science and Technology, 2(4), 9-15. doi:10.30939/ijastech..475477

Lv, C., Zhang, J., Li, Y., \& Yuan, Y. (2015). Novel control algorithm of braking energy regeneration system for an electric vehicle during safety-critical driving maneuvers. Energy Conversion and Management, 106, 520-529. doi:10.1016/j.enconman.2015.09.062

Mahayadin, A. R., Ibrahim, I., Zunaidi, I., Shahriman, A. B., Faizi, M. K., Sahari, M., ... \& Nagaya, Y. (2018, August 16-17). Development of driving cycle construction methodology in Malaysia's urban road system. In 2018 International Conference on Computational Approach in Smart Systems Design and Applications (pp. 1-5). Kuching, Malaysia.

Mcdonald, D., Sault, L., \& Marie, S. (2012, March 23-24). Electric vehicle drive simulation with MATLAB / simulink. In Proceedings of the 2012 North-Central Section Conference (pp. 1-24). Ohio, USA.

Mehrdad, E., Yimin, G., Sebastian, E. G., \& Ali, E. (2005). Modern electric, hybrid electric, and fuel cell vehicles. Ohio, USA: CRC PRESS.

Panagiotidis, M., Delagrammatikas, G., \& Assanis, D. (2018). Development and use of a regenerative braking model for a parallel hybrid electric vehicle. SAE Transactions, 109, 1180-1191.

Yeo, H., \& Kim, H. (2002). Hardware-in-the-loop simulation of regenerative braking for a hybrid electric vehicle. Journal of Automobile Engineering, 216(11), 855-864. doi:10.1243/095440702321031405 
Zhang, J., Lv, C., Qiu, M., Li, Y., \& Sun, D. (2013). Braking energy regeneration control of a fuel cell hybrid electric bus. Energy Conversion and Management, 76, 1117-1124. doi:10.1016/j.enconman.2013.09.003

Zhang, W., Yang, J., Zhang, W., \& Ma, F. (2019). Research on regenerative braking of pure electric mining dump truck. World Electric Vehicle Journal, 10(2), 1-17. doi:10.3390/wevj10020039

Zhou, M., Gao, Z., \& Zhang, H. (2011). Research on regenerative braking control strategy of hybrid electric vehicle. Proceedings of $20116^{\text {th }}$ International Forum on Strateguc Technology, 1, 300-303. doi: 10.1109/ ifost.2011.6021027 